\title{
Calabrian extra-virgin olive oil from Frantoio cultivar: chemical composition and health properties
}

\author{
Mariarosaria Leporini', Monica Rosa Loizzo ${ }^{1 *}$, Maria Concetta Tenuta ${ }^{1}$, Tiziana Falco', Vincenzo Sicari², \\ Teresa M. Pellicanò ${ }^{2}$, Rosa Tundis ${ }^{1}$ \\ ${ }^{1}$ Department of Pharmacy, Health Science and Nutrition, University of Calabria, Via P. Bucci, Edificio Polifunzionale, 87036 Rende (CS), Italy. \\ ${ }^{2}$ Department of Agraria, University "Mediterranea" of Reggio Calabria, 89124 Reggio Calabria (RC), Italy
}

\section{A B S T R A C T}

Extra virgin olive oil (EVOO) plays a crucial role in the Mediterranean diet. Recently, attention has been focused on presence in EVOO of phenolic compounds, phytochemicals characterized by a series of healthy properties. This paper analyzed the phenolic profile, the inhibitory activity against carbohydrate hydrolising enzyme as well as the radical scavenging activity of EVOO obtained from Olea europea L. cv. Frantoio. Samples derived from fruits collected in four different areas: Cariati, Vaccarizzo Albanese, Montalto Uffugo, and Praia a Mare. The phenolic profile obtained by HPLC revealed the presence of hydroxytyrosol (3,4-DHPEA, between 1.2 and $5.3 \mathrm{mg} / \mathrm{kg}$ ) and $p$-hydroxyphenylethanol or tyrosol ( $p$-HPEA, between 1.1 and $5.4 \mathrm{mg} / \mathrm{kg}$ ), as the main components. Secoiridoids and their derivatives were also found in high concentrations (3,4-DHPEA-EDA 50.3-98.4 mg/kg, $p$-HPEA-EDA 34.6-52.9 mg/kg). All samples showed carbohydrate-hydrolyzing enzymes inhibition. The most promising activity was observed with EVOO from Vaccarizzo Albanese (IC Fo $_{50}$ 65.5 and $57.7 \mu \mathrm{g} / \mathrm{ml}$ against a-glucosidase and a-amylase, respectively). The same sample showed the highest antioxidant activity of 45.3 and $56.3 \mu \mathrm{g} / \mathrm{ml}$ against DPPH and ABTS radicals, respectively. This sample was richest in phenols. In conclusion, EVOO has highlevel bioactive compounds and a promising antioxidant and hypoglycemic activity.

Keywords: Extra virgin olive oil; Frantoio cv; Antioxidant activity; Carbohydrate hydrolizing enzymes inhibition

\section{INTRODUCTION}

Extra Virgin Olive Oil (EVOO) plays a crucial role in the Mediterranean diet since it is a major source of fat. For its nutritional properties EVOO consumption has increased significantly in recent years (EEC, 2003). Italy is the second world producer with a percentage of $26 \%$. EVOO is obtained exclusively by physical methods from the fruit of Olea europea. L. Italy is the second largest EVOO producer in the Europe (EU) after Spain and accounts for approximately one-quarter of the EU-28 olive acreage. In Italy, about 600 Olea europea cultivars were grown and several cultivars are cultivated in Calabria Region (Giuffrè et al., 2014a; 2014b; Muzzalupo et al., 2014; Sicari et al., 2009; Giuffrè et al., 2010; Sicari et al., 2010). Among them, there is Frantoio cv. This cultivar which is widely terranean area and in the Italian territory (Louadj and Giuffrè, 2010; Pandolfi et al., 2017; Veneziani et al., 2018). This variety of olive presents a rather vigorous fructification and, at the same time very abundant in terms of quantity, regular, but late. EVOO derived from
Frantoio $\mathrm{cv}$ is characterized by vegetal and pungent notes (Alowaiesh et al., 2016; Bajoub et al., 2016). The biometric evaluation of Frantoio olive cultivar was recently reported by Giuffrè (2017). Frantoio cv was characterized by high flesh dry weight but at the same time low moisture content.

EVOO chemical and organoleptic properties are affected by several factors including agronomical, environmental, genetic, and technological factors (Inarejos-García et al., 2009; Morellò et al., 2006; Servili et al., 2007; OlivaresLopez et al., 2007). EVOO nutritional properties are mainly attributed to its composition which consists in a high percentage of monounsaturated acids (C18:1, between 55-83\%), minor components (alcohols, sterols and hydrocarbons) and particularly phenolic antioxidants (Consleg, 2015; COI, 2015). These minor compounds, recently, have received a great attention by scientist (Loizzo et al., 2009; Servili et al., 2013; Sicari, 2017). According to EFSA (2011), a consumption of EVOO phenols ( $5 \mathrm{mg} /$ day) is able to protect from several chronic disease. Moreover,

\footnotetext{
${ }^{*}$ Corresponding author:

Monica Rosa Loizzo, Department of Pharmacy, Health Science and Nutrition, University of Calabria, Via P. Bucci, Edificio Polifunzionale, 87036 Rende (CS), Italy. E-mail: monica_rosa.loizzo@unical.it
}

Received: 12 February 2018; $\quad$ Accepted: 19 June 2018 
EVOO phenolic compounds have a series of healthy effects including influence on glucose metabolism (Servili et al., 2013; Santangelo et al., 2016).

Diabetes mellitus (DM) is a metabolic disorders in which there is a hyperglycaemic condition over a prolonged period (IDF, 2017). This disease will reach pandemic proportion in the next twenty years. International Diabetes Federation estimated that in $2025, \mathrm{DM}$ affects 371 million people. The chronic hyperglycaemia is the consequence of a deficiency of insulin secretion from pancreatic $\beta$-cells (DM type 1 ) or insulin resistance in target tissues (DM type 2) (idf, 2017). The strictly linkage between ROS and metabolic disorder was recently demonstrated (Tangvarasittichai 2015). For this reason, EVOO phenolic compounds could be useful in the management of this disorder for two-fold reasons: antioxidant and hypoglycaemic agents.

Hydroxytyrosol and oleuropein, two of the main EVOO phenolic compounds are responsible of the bitter and pungent taste, have powerful health properties. The phenolic profile of EVOO differs according to the cultivar and during the shelf life.

The aim of this work was the evaluation of Calabrian EVOO (Italy) in terms of 1) their quality parameters (peroxide value and free acidity), 2) fatty acids methyl esters composition, 3) HPLC phenolic profile, 4) in vitro hypoglycemic activity, and 5) radicals scavenging potential.

\section{MATERIALS AND METHODS}

\section{Standards, reagents and solvents}

3,4-Dihydroxyphenylacetic acid, apigenin, p-hydroxyphenyl ethanol, fatty acid methyl esters standard, luteolin, vanillic acid, vanillin, were purchased from Sigma (Milan, Italy). All solvents used were analytical or HPLC grade (VWR, Milan Italy).

\section{Samples}

Olives cultivated in different area of Cosenza province (Calabria, Italy) harvested in autumn 2015 were collected and used to prepare extra virgin olive oils (EVOO). In particular, after cleaning, fruits were grinding into a paste by a hammer crusher. The malaxation of the olive paste (30 min) was done in a horizontal mixer successively a three-phase decanter was applied. The oil was centrifuged and filtrated. Samples were stored at $10{ }^{\circ} \mathrm{C}$ in dark without headspace up to analysis. Table 1 reported the cultivar and area of cultivation.

\section{Determination of legal quality parameters}

The peroxide value and free acidity were determined according to the EEC 1991 standard methods.
Fatty acid methyl esters analysis by gas chromatography Fatty acid methyl esters (FAMEs) from the oil samples were obtained as previously described (Christie, 1998). The FAMEs were identified by their retention times in comparison with an authentic standard mix containing the FAMEs from C10 to C22.

\section{EVOO Phenolic fraction}

EVOO Phenolic fraction was obtained following Montedoro et al. (1992) procedure and then dried by using a rotary evaporation. Samples for spectrophotometric and HPLC analysis were resuspended in methanol.

High performance liquid chromatography of phenols The qualitative and quantitative characterization of the phenolic compounds was performed using high performance liquid chromatography (HPLC) with a diode array detector (DAD) using the procedure described by Boselli et al., (2007). All phenolic compounds were quantified using a calibration curve obtained with 3,4-dihydroxyphenylacetic acid $\left(r^{2}=0.998\right)$, whereas flavones were quantified with quercetin $\left(r^{2}=0.998\right)$. For structural elucidation, the HPLC system was coupled online to an LCQ ion-trap mass spectrometer (Thermoquest, San José, CA, USA) equipped with an electrospray ionization source suitable for tandem mass spectrometry (MS/MS). The LC effluent was split and $0.1 \mathrm{ml} / \mathrm{min}$ entered the mass spectrometer through a steel ionization needle set at $4 \mathrm{kV}$ and a heated capillary set at $200{ }^{\circ} \mathrm{C}$. The sheath gas flow was approximately 70 arbitrary units. Tandem mass experiments were performed with relative collision energy of $30-40 \%$. All of the data were acquired with Excalibur software Version 1.2 (Thermoquest, San José, CA, USA).

\section{Inhibition of carbohydrate-hydrolyzing enzymes}

The $\alpha$-amylase inhibitory activity was studied following the previously reported method (Loizzo et al. (2008). Briefly, a starch solution was prepared by mixing potato starch in 20 $\mathrm{mM}$ sodium phosphate buffer with $6.7 \mathrm{mM}$ sodium chloride while enzyme solution by mixing $\alpha$-amylase (10 units/mg) in $100 \mathrm{ml}$ of distilled cold water. The colorimetric reagent was obtained by mixing a potassium tartrate solution of sodium and a $96 \mathrm{mM}$ solution of 3,5-dinitrosalicylic acid.

Table 1: EVOO from O. europea cv Frantoio samples (growing area; latitude and longitude)

\begin{tabular}{llcc}
\hline Samples & Area & Latitude & Longitude \\
\hline 1 & Cariati & $39^{\circ} 29^{\prime} 35^{\prime \prime} 52$ & $16^{\circ} 57^{\prime} 36^{\prime \prime} 72$ \\
& & $\mathrm{~N}$ & $\mathrm{E}$ \\
2 & Vaccarizzo & $39^{\circ} 35^{\prime} 11^{\prime \prime} 04$ & $16^{\circ} 26^{\prime} 1^{\prime \prime} 32$ \\
& Albanese & $\mathrm{N}$ & $\mathrm{E}$ \\
3 & Montalto Uffugo & $39^{\circ} 24^{\prime} 20^{\prime \prime} 88$ & $16^{\circ} 9^{\prime} 31^{\prime \prime} 68$ \\
& & $\mathrm{~N}$ & $\mathrm{E}$ \\
4 & Praia a mare & $39^{\circ} 54^{\prime} 66^{\prime \prime} 84 \mathrm{~N}$ & $15^{\circ} 46^{\prime} 48^{\prime \prime} 36$ \\
& & & $\mathrm{E}$ \\
\hline
\end{tabular}


Maltose production was quantified by the reduction of 3,5-dinitrosalicylic acid to acid 3 amino-5-nitrosalicilic. The inhibition of $\alpha$-amylase was expressed as a percentage of inhibition.

For the $\alpha$-glucosidase inhibition test the modified SigmaAldrich procedure was applied (Loizzo et al., 2008). Briefly, a malt solution was prepared, enzyme solution of $\alpha$-glucosidase (10 units $/ \mathrm{mg}$ ) in $10 \mathrm{ml}$ of distilled water, a colorimetric solution of DIAN, whereas the PGO enzymecolor reagent solution was freshly prepared by dissolving one capsule in $100 \mathrm{ml}$ of ice-cold distilled water. In the first step, both the control and the extracts were combined with the maltose solution. The reaction started with the addition of the enzyme solution; subsequently, perchloric acid $(4.2 \% \mathrm{w} / \mathrm{v})$ was added to block the reaction. In the second step, glucose production was quantified by DIAN reduction, the supernatant was mixed with DIAN and PGO and incubated at $37^{\circ} \mathrm{C}$ for $30 \mathrm{~min}$. The inhibition of $\alpha$-glucosidase was expressed as a percentage of inhibition. Acarbose was used as positive control in both assays.

\section{Radical scavenging activity}

The radical scavenging activity was investigated by2,2diphenyl-1-picrylhydrazyl (DPPH) radical scavenging assay and 2,2'-azinobis (3-etilbenzotiazolin-6-sulfonic acid) ABTS assay. For DPPH analysis the procedure previously reported was applied Loizzo et al. (2015). The DPPH test is based on measurement of the scavenging capacity of antioxidants towards DPPH radical. A decrease in absorbance of the DPPH solution indicates an increase in the radical DPPH scavenging activities. Ascorbic acid was used as positive control. The ABTS test was performed on the procedure described by Sicari et al. (2016) with minor modifications. ABTS. ${ }^{+}$radical cation was obtained by reaction of ABTS to potassium persulfate. After $12 \mathrm{~h}$ the solution was diluted with ethanol to reach an absorbance of $0.70-0.05$ to $734 \mathrm{~nm} ; 25 \mu \mathrm{L}$ of different concentration of extracts was added and the absorbance was measured.

\section{Relative Antioxidant Capacity Index (RACI) calculation} RACI is a statistical application used to evaluate the antioxidant capacity of samples (Sun et al., 2007). The standard score is calculated as follows: $(\mathrm{x}-\mu) / \sigma$, where $\mathrm{x}$ is the raw data, $\mu$ is the mean, and $\sigma$ is the standard deviation.

\section{Global Antioxidant Score (GAS)}

For each EVOO extract, the average of T-scores was used to calculate the value of Global Antioxidant Score (GAS). T-score is calculated by the following equation: $\mathrm{T}-$ score $=(\mathrm{X}-\min ) /(\max -\min )$, where min and max, respectively, represent the smallest and largest values of variable $\mathrm{X}$ among the investigated extract (Leeuw et al., 2014).

\section{Statistical analysis}

All data were expressed as means \pm standard deviation $(\mathrm{SD})(\mathrm{n}=3)$. The inhibitory concentration 50\% (IC50) was calculated by nonlinear with the use of Prism Graphpad Prism version 4.0 for Windows, GraphPad Software, San Diego, CA, USA. Differences were evaluated by ANOVA test followed by multicomparison Dunnett's test. The concentration-response curve was obtained by plotting the percentage of inhibition versus the concentrations.

\section{RESULTS AND DISCUSSION}

\section{Quality parameters}

Calabrian EVOO peroxide levels ranged from 3.6 to $6.3 \mathrm{meq}_{2} / \mathrm{kg}$ of oil for samples coming from Praia a mare and Cariati while free acidity values ranged from 0.2 to $0.4 \mathrm{~g}$ oleic acid/100 g oil for Vaccarizzo Albanese and Montalto Uffugo, respectively while the (Table 2). The data obtained indicated that all the analyzed oil samples are "extra virgin" according to the EC 2568/91 regulation. A lower acidity values were found for EVOO derived from Frantoio cv while similar values were recorded in Leccino, Moraiolo, Taggiasca and Pendolino cv. EVOO from Frantoio cv grown in Veneto Region (Italy) showed a similar peroxide value of 3.4 meq $\mathrm{O}_{2} / \mathrm{kg}$ oil (Lavelli et al. 2005). EVOO from Coratina cv typical of Puglia Region (Italy) showed a peroxide value of 4.93 meq $\mathrm{O}_{2} / \mathrm{kg}$ and acidity value of $0.25 \%$ (Gambacorta et al. 2010).

\section{EVOO total phenols content}

Phenolic compounds characterized by antioxidant properties are very important to preserve EVOO quality. As it is possible to see in Table 2 the total phenols content ranged from 94.6 to $256 \mathrm{mg}$ gallic acid/ $\mathrm{kg}$ oil for Montalto Uffugo and Vaccarizzo Albanese sample, respectively. Our results are in line with those reported by Loizzo et al. (2009) for EVOO from Campania region (Italy). A higher value was found in EVOO from Bosana cv (Sardinia, Italy) (Del Caro et al., 2006).

\section{Fatty acid methyl ester profile}

All samples presented a high content of oleic acid (C18:1) with values ranging from $72.7 \%$ to $75.5 \%$ for Vaccarizzo Albanese and Cariati EVOO, respectively. Oleic acid contributed to most of the total concentration of monounsaturated fatty acid (MUFA) (Table 3).

Among saturated fatty acid (SFA) palmitic acid (C16:0) showed the highest value with percentages of 13.0, 12.9, $11.8,11.9 \%$ for Cariati, Vaccarizzo Albanese, Montalto Uffugo and Praia a mare respectively while linoleic (C18:2) was the most abundant polyunsaturated fatty acid 
Table 2: Calabrian extra-virgin olive oil from Frantoio cultivar quality parameters, total phenols and the Rancimat time: a oleic acid in $100 \mathrm{~g}$ of oil; ${ }^{\mathrm{b}} \mathrm{meq} \mathrm{O}_{2} / \mathrm{kg}$ oil; ${ }^{\mathrm{c}} \mathrm{mg}$ of gallic acid $/ \mathrm{kg}$ of oil; ${ }^{d}$ hours

\begin{tabular}{lcccc} 
& $\mathbf{1}$ & $\mathbf{2}$ & $\mathbf{3}$ & $\mathbf{4}$ \\
\hline Free acidity $^{\mathrm{a}}$ & $0.3 \pm 0.0$ & $0.2 \pm 0.0$ & $0.4 \pm 0.1$ & $0.4 \pm 0.1$ \\
Peroxide value $^{\mathrm{b}}$ & $6.3 \pm 0.9$ & $6.3 \pm 0.9$ & $6.2 \pm 0.6$ & $3.6 \pm 0.9$ \\
Total phenols $^{\mathrm{c}}$ & $204.0 \pm 5.5$ & $256.0 \pm 2.8$ & $94.6 \pm 1.5$ & $168.0 \pm 6.2$ \\
Rancimat time $^{\mathrm{d}}$ & $26.5 \pm 1.1$ & $27.8 \pm 1.5$ & $13.1 \pm 1.1$ & $17.8 \pm 1.2$ \\
\hline
\end{tabular}

Table 3: Fatty acids composition per cent of Calabrian extra-virgin olive oil from Frantoio cultivar.

\begin{tabular}{lcccc} 
& $\mathbf{1}$ & $\mathbf{2}$ & $\mathbf{3}$ & $\mathbf{4}$ \\
\hline $\mathrm{C} 16: 0^{\mathrm{a}}$ & $13.0 \pm 1.5$ & $12.9 \pm 1.7$ & $11.8 \pm 1.4$ & $11.9 \pm 1.4$ \\
$\mathrm{C} 16: 1^{\mathrm{a}}$ & $0.7 \pm 0.1$ & $0.9 \pm 0.1$ & $0.6 \pm 0.1$ & $0.9 \pm 0.0$ \\
$\mathrm{C} 17: 0$ & $0.2 \pm 0.0$ & $0.1 \pm 0.0$ & $0.2 \pm 0.0$ & $0.2 \pm 0.0$ \\
$\mathrm{C} 17: 1$ & $0.3 \pm 0.0$ & $0.3 \pm 0.0$ & $0.2 \pm 0.1$ & $0.3 \pm 0.1$ \\
$\mathrm{C} 18: 0^{\mathrm{a}}$ & $1.9 \pm 0.9$ & $2.6 \pm 0.9$ & $2.3 \pm 0.8$ & $2.5 \pm 0.9$ \\
$\mathrm{C} 18: 1^{\mathrm{a}}$ & $75.5 \pm 5.6$ & $72.7 \pm 3.5$ & $75.1 \pm 3.7$ & $73.9 \pm 5.8$ \\
$\mathrm{C} 18: 2^{\mathrm{a}}$ & $6.2 \pm 1.1$ & $7.7 \pm 0.9$ & $7.4 \pm 1.1$ & $8.2 \pm 1.4$ \\
$\mathrm{C} 20: 0^{\mathrm{a}}$ & $0.4 \pm 0.4$ & $0.7 \pm 0.0$ & $0.6 \pm 0.1$ & $0.5 \pm 0.0$ \\
$\mathrm{C} 20: 1+\mathrm{C} 18: 3^{\mathrm{a}}$ & $0.8 \pm 0.5$ & $0.8 \pm 0.0$ & $0.7 \pm 0.0$ & $0.7 \pm 0.0$ \\
$\mathrm{C} 20: 2^{\mathrm{a}}$ & $1.0 \pm 0.0$ & $1.2 \pm 0.1$ & $1.0 \pm 0.1$ & $0.9 \pm 0.0$ \\
$\mathrm{C} 22: 0^{\mathrm{a}}$ & $\mathrm{N} . \mathrm{D}$. & $0.1 \pm 0.0$ & $0.1 \pm 0.0$ & $\mathrm{~N} . \mathrm{D}$. \\
$\mathrm{C} 18: 1 / \mathrm{C} 18: 2$ & $12.2 \pm 1.7$ & $9.4 \pm 1.0$ & $10.1 \pm 1.2$ & $9.0 \pm 1.0$ \\
\hline
\end{tabular}

${ }^{\mathrm{a}} \mathrm{C} n$ : $\mathrm{m} . \mathrm{n}=$ number of carbon atoms; $\mathrm{m}=$ number of double bonds. N.D.: not detected.

(PUFA). EVOO from Praia a mare showed the highest content $(8.2 \%)$.

Higher C18:2 values (14.2-14.8\%) were recorded in EVOO obtained from Argentinian Frantoio cultivar (Ceci and Carelli, 2007). In comparison with our data, Argentinian oils showed a lower oleic acid content (63.1-63.4\% vs 72.7-75.5\%). Our results are in agreement with those reported by Katsoyannos et al. (2015) for Megaritiki and Koroneiki varieties.

Similar values were observed also by Patumi et al. (2003) in Sicilian Nocellara del Belice, Nocellara Etnea, Moresca, Cerasuola and Biancolilla. A high oleic/linoleic ratio, that theoretically measure the stability of the oil (Alvarruiz et al., 2003), was found for all samples with particular reference to EVOO from Cariati in which this value was 12.2 .

\section{Characterization of phenolic fractions}

HPLC-DAD was used to investigate Calabrian EVOO phenolic profile. 3,4-DHPEA and p-hydroxyphenylethanol showed values in the range from 1.2 to $5.3 \mathrm{mg} / \mathrm{kg}$ for 3,4-DHPEA in samples 3 and 1, respectively and from 1.1 and $5.4 \mathrm{mg} / \mathrm{kg}$ oil for the same samples for p-hydroxyphenylethanol (Table 4). A similar 3,4-DHPEA and $p$-hydroxyphenylethanol content was observed in EVOO from Campania (Loizzo et al., 2009).
Secoiridoids and their derivatives were also found in high concentrations in all samples, in particular high values were recorded for 3,4-DHPEA-EDA (50.3$98.4 \mathrm{mg} / \mathrm{kg}$ oil), $p$-HPEA-EDA (34.6-52.9 mg/ $\mathrm{kg}$ oil) and $p$-HPEA-EDA oxidized (28.2-60.4 mg/kg oil). Among identified compounds were also quantified vanillin and vanillic acid (1-2 mg/kg oil and $0.9-3.5 \mathrm{mg} / \mathrm{kg}$ oil), p-cumaric acid ( 0.8 to $2.7 \mathrm{mg} / \mathrm{kg}$ oil), apigenin $(0.7-1.4 \mathrm{mg} /$ $\mathrm{kg}$ oil) and luteolin (1.9-2.9 mg/kg oil). Regarding flavones, lutein showed the highest concentration in EVOO from Cariati while Montalto Uffugo sample was richest in apigenin. Calabrian oil showed a high content of luteolin in comparison with those obtained from Campania region but not for apigenin (Loizzo et al., 2009). A high content of tyrosol and 3,4-DHPEA was quantified by Servili et al. (2007) in Coratina and Frantoio cv from Puglia region, and Sicari (2017) in Sinopolese, Roggianella and Ottobratica cv from Calabria region. Recently, high levels of 3,4-DHPEAEDA and 3,4-DHPEA-EA were found in Umbrian EVOO from Frantoio by Veneziani et al. (2018). However these oils are extracted using a cooling treatment of olive paste.

\section{Carbohydrate-hydrolysing enzymes inhibitory activity of Calabrian EVOO}

The inhibition of carbohydrate hydrolysing enzymes is a common strategy to treat DM (Loizzo et al., 2017). All extracts exhibited a concentration-dependent activity against these enzymes. In particular, the most promising activity was observed for sample 2 with $\mathrm{IC}_{50}$ values of 57.7 and $65.5 \mu \mathrm{g} / \mathrm{ml}$ for $\alpha$-amylase and $\alpha$-glucosidase respectively (Table 5). The hypoglycaemic effect of Calabrian samples was higher than those reported for Campania region (Loizzo et al., 2009). Recently, the strong hypoglycaemic effect of Spanish EVOO extract derived from Arbequina, Picual, Cuquillo, Cornicabra, and Hojiblanca was demonstrated (Collado-González et al., 2017). The relationship between carbohydrate-hydrolysing enzyme inhibition and phenolic content was proved by several research articles. In particular, hydroxytyrosol is a potent inhibitor of $\alpha$-glucosidase ( $\mathrm{IC}_{50}$ value of $150 \mu \mathrm{M}$ ) (Hdrich et al., 2015). This value was lower than acarbose $(200 \mu$ M). Previously, Loizzo et al. (2009) reported luteolin carbohydrate hydrolysing inhibitory activity with $\mathrm{IC}_{50}$ values of $0.36 \mathrm{mM}$ and $21 \mu \mathrm{M}$ against $\alpha$-amylase and $\alpha$-glucosidase. More recently, Zeng et al. (2016) demonstrated the ability to apigenin to act as $\alpha$-glucosidase reversible inhibitor $\left(\mathrm{IC}_{50}\right.$ value of $10.5 \mu \mathrm{M})$ as well as tyrosol $\left(\mathrm{IC}_{50}\right.$ value of $\left.70.8 \mu \mathrm{M}\right)$ (Chandramohan et al., 2015). Several different mechanisms of action could contribute to the hypoglycaemic activity of the EVOO and for this reason should be considered. For example, this phenylethanoid orally administered in streptozotocin-induced diabetic rats protect from the altered glycoprotein components since it reduces plasma glucose level and glycosylated hemoglobin and increases 
Table 4: Phenolic compounds quantified in different samples of Calabrian extra-virgin olive oil from Frantoio cultivar

\begin{tabular}{lcccc}
\hline & $\mathbf{1}$ & $\mathbf{2}$ & $\mathbf{3}$ & $\mathbf{4}$ \\
\hline 3,4-DHPEA $^{\mathrm{a}}$ & $5.3 \pm 0.9$ & $4.6 \pm 0.7$ & $1.2 \pm 0.4$ & $1.7 \pm 0.1$ \\
p-HPEA $^{\mathrm{a}}$ & $5.4 \pm 0.7$ & $2.5 \pm 0.3$ & $1.1 \pm 0.2$ & $1.7 \pm 0.5$ \\
Vanillic Ac $^{\mathrm{a}}$. & $3.5 \pm 0.2$ & $1.7 \pm 0.5$ & $0.9 \pm 0.0$ & $\mathrm{~N} . \mathrm{D}$. \\
Vanillin $^{\mathrm{a}}$ & 2.0 & $1.0 \pm 0.2$ & $1.1 \pm 0.7$ & $0.9 \pm 0.0$ \\
3,4-DHPEA-Ac $^{\mathrm{a}}$ & $\mathrm{N} . \mathrm{D}$. & $1.9 \pm 0.3$ & $\mathrm{~N} . \mathrm{D}$. & $0.7 \pm 0.1$ \\
p-Coumaric $^{\mathrm{a}}$ & $2.7 \pm 0.4$ & $0.8 \pm 0.1$ & $0.8 \pm 0.0$ & $0.9 \pm 0.1$ \\
3,4-DHPEA-EDA $^{\text {a }}$ & $98.4 \pm 3.5$ & $50.3 \pm 2.8$ & $89.4 \pm 2.9$ & $56.0 \pm 3.1$ \\
3,4-DHPEA-EDA-Ox $^{\mathrm{a}}$ & $2.6 \pm 0.8$ & $7.0 \pm 0.9$ & $1.7 \pm 0.6$ & $5.8 \pm 0.9$ \\
p-HPEA-EDA $^{\text {a }}$ & $52.9 \pm 1.7$ & $34.9 \pm 1.7$ & $37.9 \pm 1.6$ & $34.6 \pm 2.7$ \\
p-HPEA-EDA-Ox $^{\mathrm{a}}$ & $28.2 \pm 2.9$ & $37.6 \pm 1.9$ & $60.4 \pm 1.8$ & $35.9 \pm 3.4$ \\
3,4-DHPEA-EA & $27.5 \pm 1.6$ & $22.5 \pm 2.2$ & $19.0 \pm 1.7$ & $18.9 \pm 1.9$ \\
Ligustroside aglycon $^{\text {a }}$ & $4.4 \pm 0.9$ & $3.0 \pm 0.9$ & $\mathrm{~N} . \mathrm{D}$. & $1.7 \pm 0.9$ \\
Luteolin $^{\mathrm{b}}$ & $2.9 \pm 0.5$ & $2.2 \pm 0.7$ & $2.8 \pm 0.9$ & $1.9 \pm 0.5$ \\
Apigenin $^{\mathrm{b}}$ & $1.1 \pm 0.4$ & $1.1 \pm 0.3$ & $1.4 \pm 0.5$ & $0.7 \pm 0.1$ \\
\hline
\end{tabular}

3,4-DHPEA: 3,4-dihydroxyphenylethanol; $p$-HPEA:

p-hydroxyphenylethanol; 3,4-DHPEA-Ac: 3,4-dihydroxyphenylethanol-acetate; 3,4-DHPEA-EDA: dialdehydic form of decarboxymethyl elenolic acid linked to 3,4-DHPEA; 3,4-DHPEA-EDA oxidized; $p$-HPEA-EDA: dialdehydic form of decarboxymethyl elenolic acid linked to $p$-HPEA; $p$-HPEA-EDA-oxidized; 3,4-DHPEA-EA: oleuropein aglycon; amg $p$-hydroxyphenylethanol $/ \mathrm{kg}$ of oil; ${ }^{\mathrm{b}} \mathrm{mg}$ quercetin/kg of oil. N.D.: Not detected.

Table 5: Carbohydrate enzymes inhibitory activity $\left(\mathrm{IC}_{50} \mu \mathrm{g} / \mathrm{ml}\right)$ of Calabrian extra-virgin olive oil from Frantoio cultivar

\begin{tabular}{lll}
\hline Sample & $\alpha$-Amylase & $\alpha$-Glucosidase \\
\hline 1 & $72.3 \pm 1.8^{\star \star \star}$ & $76.5 \pm 2.0^{\star \star \star}$ \\
2 & $57.7 \pm 1.5^{\star \star *}$ & $65.5 \pm 1.8^{\star \star *}$ \\
3 & $123.7 \pm 3.9^{\star \star *}$ & $167.7 \pm 3.7^{\star \star *}$ \\
4 & $82.6 \pm 2.5^{\star \star *}$ & $143.9 \pm 3.8^{\star * \star}$ \\
Acarbose & $50.0 \pm 0.9$ & $35.5 \pm 1.2$ \\
\hline
\end{tabular}

Acarbose was used as positive control. $\alpha$-Amylase: One-way ANOVA ${ }^{* \star *} p<0.0001$ followed by a multicomparison Dunnett's test: $* * *$ $p<0.01$ compared with acarbose; $\alpha$-Glucosidase: One-way ANOVA *** $p<0.0001$ followed by a multicomparison Dunnett's test: ${ }^{* *} p<0.0001$ compared with acarbose

Table 6: Antioxidant activity $\left(\mathrm{IC}_{50} \mu \mathrm{g} / \mathrm{ml}\right)$ of Calabrian extra-virgin olive oil from Frantoio cultivar

\begin{tabular}{lcc}
\hline & DPPH test & ABTS test \\
\hline 1 & $67.4 \pm 1.2^{\star * \star}$ & $61.6 \pm 1.7^{\star \star *}$ \\
2 & $45.3 \pm 1.8^{\star \star *}$ & $56.3 \pm 1.2^{\star \star \star}$ \\
3 & $256.8 \pm 4.3^{\star *}$ & $279.6 \pm 2.7^{\star \star \star}$ \\
4 & $98.6 \pm 2.8^{\star * *}$ & $130.0 \pm 2.9^{\star \star \star}$ \\
Ascorbic acid & $5.0 \pm 2.6$ & $1.7 \pm 0.9$ \\
\hline
\end{tabular}

Ascorbic acid was used as positive control. DPPH: One-way ANOVA ${ }^{* * *} p<0.0001$ followed by a multicomparison Dunnett's test: ${ }^{* * *} p<0.01$ compared with ascorbic acid; ABTS: One-way ANOVA ${ }^{* * *} p<0.001$ followed by a multicomparison Dunnett's test: ${ }^{* * *} p<0.01$ compared with ascorbic acid.

insulin secretion by $\beta$-cells (Chandramohan et al., 2015). The induction of GLUT-4 translocation by luteolin was also demonstrated (Li et al., 2007; Berger et al. 1989; Sivitz et al., 1989). A positive effect in type 2 diabetes model was observed also with apigenin although with a different mechanism that determined a reduction of oxidative stress and inflammation (Ren et al., 2016).

\section{Radicals scavenging activity}

The radical scavenging activity properties of EVOO samples were examined using DPPH and ABTS test. Data are reported in Table 6. ABTS. ${ }^{+}$and DPPH radicals have a different stereochemistry and a different training mechanism and therefore, after reaction with antioxidants, they give a qualitatively different response to the inactivation of their radical (Antolovich et al., 2002).

All samples showed concentration-dependent antioxidant effects (Table 6). The most promising scavenging capacity was observed with EVOO extract from Vaccarizzo Albanese with IC $_{50}$ values of 45.3 and $56.3 \mu \mathrm{g} / \mathrm{ml}$ respectively for DPPH and ABTS test followed by Cariati sample $\left(\mathrm{IC}_{50}\right.$ values of 67.4 and $61.6 \mu \mathrm{g} / \mathrm{ml}$ respectively for DPPH and ABTS test).

Based on RACI and GAS the following antioxidant rank of order has been found: Vaccarizzo Albanese EVOO > Cariati EVOO > Praia a Mare EVOO > Montalto Uffugo EVOO. The antioxidant potential of EVOO phenolic extract assessed by different in vitro methods were largely described in literature (Del Caro et al., 2006; Lavelli et al., 2005; Katsoyannos et al., 2015).

\section{CONCLUSIONS}

EVOO is recognized as one of the condiment mostly consumed in the Mediterranean area for its role in preventing several diseases including diabetes. Recently, there is a great interest in EVOO minor abundant compounds and in particular to phenolic compounds for their healthy properties. Calabrian EVOOs obtained by $O$. europea Frantoio cv are rich in phenolic compounds and in unsaturated fatty acids. In particular, the most promising health properties was observed for extract derived by EVOO from Vaccarizzo Albanese. In conclusion, the consumption of EVOOs from Frantoio cv present sjould be recommended not only for its high quality but also for its healthy properties.

\section{REFERENCES}

Alowaiesh, B., Z. Singh and S. G. Kailis. 2016. Harvesting time influences fruit removal force, moisture, oil content, free fatty acids and peroxide in the oil of Frantoio and Manzanilla olive cultivars. Aust. J. Crop Sci. 10: 1662-1668.

Alvarruiz, A., E. Fernández, F. Montero, J. Granell and J. E. Pardo. 2003. Analytical evaluation of 'Cornicabra' virgin olive oil from Castilla-La Mancha, Spain. J. Food Agric. Environ. 1: 48-52.

Antolovich, M., P. D. Prenzler, E. Patsalides, S. McDonald and K. Robards. 2002. Methods for testing antioxidant activity. Analyst. 127: 183-198.

Bajoub, A., T. Pacchiarotta, E. Hurtado-Fernández, L. Olmo-García, 
R. García-Villalba, A. Fernández-Gutiérrez, O. A. Mayboroda and A. Carrasco-Pancorbo. 2016. Comparing two metabolic profiling approaches (liquid chromatography and gas chromatography coupled to mass spectrometry) for extra-virgin olive oil phenolic compounds analysis: A botanical classification perspective. J. Chromatogr. A. 1428: 267-279.

Berger, J., C. Biswas, P. P. Vicario, H. V. Strout, R. Saperstein and P. F. Pilch. 1989. Decreased expression of the insulinresponsive glucose transporter in diabetes and fasting. Nature. 340: 70-72.

Boselli, E., G. Di Lecce, M. Minardi, D. Pacetti and N. G. Frega. 2007. La spettrometria di massa nell'analisi di componenti minori polari dell'olio vergine di oliva. Riv. Ital. Sostanze Gr. 84: 3-14.

Ceci, L. N. and A. A. Carelli. 2007. Characterization of monovarietal Argentinian olive oils from new productive zones. J. Am. Oil Chem. Soc. 84: 1125-1136.

Chandramohan, R., L. Pari, A. Rathinam and B. A. Sheikh. 2015. Tyrosol, a phenolic compound, ameliorates hyperglycemia by regulating key enzymes of carbohydrate metabolism in streptozotocin induced diabetic rats. Chem. Biol. Interact. 5: 44-54.

Christie, W. W. 1998. The preparation of derivatives of fatty acid. In: Gas Chromatography and Lipids, The Oily Press, Dundee, pp. 64-84.

COI/T.15/NC No 3/Rev. 9 June. 2015. International Olive Council. Trade Standard Applying to Olive Oils and Olive-Pomace Oils.

Collado-González, J., C. Grosso, P. Valentão, P. B.Andrade, F. Ferreres, T. Durand, A. Guy, J. M. Galano, A. Torrecillas and Á. GilIzquierdo. 2017. Inhibition of a-glucosidase and $\alpha$-amylase by Spanish extra virgin olive oils: The involvement of bioactive compounds other than oleuropein and hydroxytyrosol. Food Chem. 235: 298-307.

Consleg. 2015. Consolidated Text. Characteristics of Olive Oil. 1991R2568 - EN - 01.01.2015 -027.001 on the Characteristics of Olive Oil and Olive-Residue Oil and on the Relevant Methods of Analysis.

Del Caro, A., V. Vacca, M. Poiana, P. Fenu and A. Piga. 2006. Influence of technology, storage and exposure on components of extra virgin olive oil (Bosana cv) from whole and de-stoned fruits. Food Chem. 98: 311-316.

EEC. 2003. Characteristics of Olive and Olive-Pomace Oils and on their Analytical Methods. Official Journal of the European Communities, L295, 57-77. Regulation EEC/2568/91, Regulation EEC/ 1989/03.

EFSA Panel on Dietetic Products, Nutrition and Allergies (NDA). 2011. Scientific Opinion on the substantiation of health claims related to polyphenols in olive and protection of LDL particles from oxidative damage (ID 1333, 1638, 1639, 1696, 2865) pursuant to Article 13(1) of Regulation (EC) No 1924/2006. EFSA J. 9: 1-25.

Gambacorta, G., M. Faccia, M. A. Previtali, S. Pati, E. La Notte and A. Baiano. 2015. Effects of olive maturation and stoning on quality indices and antioxidant content of extra virgin oils (cv. Coratina) during Storage. Food Chem. 75: C229-C235.

Giuffrè, A. M., A. Piscopo, V. Sicari and M. Poiana. 2010. The effects of harvesting on phenolic compounds and fatty acids content in virgin olive oil (cv. Roggianella). Riv. Ital. Sostanze Gr. 87: 14-23.

Giuffrè, A. M. 2014a. Evolution of fatty alcohols in olive oils produced in Calabria (Southern Italy) during fruit ripening. J. Oleo Sci. 63: 485-496.

Giuffrè, A. M. 2014b. Variation in triacylglycerols of olive oils produced in Calabria (Southern Italy) during olive ripening. Riv. Ital. Sostanze Gr. 91: 221-240.
Giuffrè, A. M. 2017. Biometric evaluation of twelve olive cultivars under rainfed conditions in the region of Calabria, South Italy. Em. J. Food Agric. 29: 696-709.

Hdrich, F., Z. Bouallagui, H. Junkyu, H. Isoda and S. Sayadi. 2015. The $\alpha$-glucosidase and $\alpha$-amylase enzyme inhibitory of hydroxytyrosol and oleuropein. J. Oleo Sci. 64: 835-843.

idf. 2017. International Diabetes Federation. Available from: http:// www.idf.org. [Last accessed on 2017 Nov 16].

Inarejos-García, A. M., A. Gómez-Rico, M. D. Salvador and G. Fregapane. 2009. Influence of malaxation conditions on virgin olive oil yield, overall quality and composition. Eur. Food Res. Technol. 228: 671-677.

Katsoyannos, E., A. Batrinou, A. Chatzilazarou, S. M. Bratakos, K. Stamatopoulos and V. J. Sinanoglou. 2015. Quality parameters of olive oil from stoned and nonstoned Koroneiki and Megaritiki Greek olive varieties at different maturity levels. Grasas Aceites. 66: e067.

Lavelli, V. and L. Bondesan. 2005. Secoiridoids, tocopherols, and antioxidant activity of monovarietal extra virgin olive oils extracted from destoned fruits. J. Agric. Food Chem. 53: 1102-1107.

Leeuw, R. W., C. Kevers, J. Pincemail, J. O. Defraigne and J. Dommes. 2014. Antioxidant capacity and phenolic composition of red wines from various grape varieties: specificity of Pinot Noir. J. Food Compos. Anal. 36: 40-50.

Loizzo, M. R., R. Tundis, F. Menichini, G. A. Statti and F. Menichini. 2008. Influence of ripening stage on health benefits properties of Capsicum annuum var. Acuminatum L.: In vitro studies. J. Med. Food. 11: 184-189.

Loizzo, M. R., G. Di Lecce, E. Boselli, F. Menichini and N. G. Frega. 2009. Inhibitory activity of phenolic compounds from extra virgin olive oils on the enzymes involved in diabetes, obesity and hypertension. J. Food Biochem. 35: 381-399.

Loizzo, M. R., D. Pacetti, P. Lucci, O. Núñez, F. Menichini, N. G. Frega and R. Tundis. 2015. Prunus persica var. Platycarpa (Tabacchiera Peach): Bioactive compounds and antioxidant activity of pulp, peel and seed ethanolic extracts. Plant Foods Hum. Nutr. 70: 331-337.

Loizzo, M. R., M. Bonesi, S. M. Nabavi, E. Sobarzo-Sánchez, L. Rastrelli and R. Tundis. 2017. In: P. B. Andrade, P. Valentão and D. M. Pereira (Eds.), Hypoglycaemic Effects of Plants Food Constituents via Inhibition of Carbohydrate-hydrolysing Enzymes: From Chemistry to Future Applications, in Natural Products Targeting Clinically Relevant Enzymes, Vol. 6, WileyVCH Verlag GmbH \& Co. KGaA, Weinheim, pp. 135-161.

Louadj, L. and A. M. Giuffrè. 2010. Analytical characteristics of olive oil produced with three different processes in Algeria. Riv. Ital. Sostanze Gr. 87: 186-195.

Montedoro, G. F., M. Servili, M. Baldioli and E. Miniati. 1992. Simple and hydrolyzable phenolic compounds in virgin olive oil. 1. Their extraction, separation and quantitative compounds and semiquantitative evaluation by HPLC. J. Agric. Food Chem. 40: 1571-1576.

Morellò, J. R., M. P. Romero and M. J. Motilva. 2006. Influence of seasonal conditions on the composition and quality parameters of monovarietal virgin olive oils. J. Am. Oil Chem. Soc. 83: 683-688.

Muzzalupo, I., G. G. Vendramin and A. Chiappetta. 2014. Genetic biodiversity of Italian olives (Olea europaea) germplasm analyzed by SSR markers. Sci. World J. 2014: 296590-11.

Olivares-Lopez, M. J., M. Innocenti, C. Giaccherini, F. leri, A. Romani and N. Mulinacci. 2007. Study of the phenolic composition of Spanish and Italian monocultivar extra virgin olive oils: Distribution of lignans, secoiridoidic, simple phenols and 
flavonoids. Talanta. 73: 726-732.

Pandolfi, C. N. Bazihizina, C. Giordano, S. Mancuso, E. Azzarello. 2017. Salt acclimation process: A comparison between a sensitive and a tolerant Olea europaea cultivar. Tree Physiol. 37: 380-388.

Patumi, M., S. Terenziani, M. Ridolfi and G. Fontanazza. 2003. Effect of fruit stoning on olive oil quality. J. Am. Oil Chem. Soc. 80: 249-255.

Ren, B., W. Qin, F. Wu, S. Wang, C. Pan, L. Wang, B. Zeng, S. Ma and J. Liang. 2016. Apigenin and naringenin regulate glucose and lipid metabolism, and ameliorate vascular dysfunction in Type 2 diabetic rats. Eur. J. Pharmacol. 15: 13-23.

Santangelo, C., C. Filesi, R. Varì, B. Scazzocchio, T. Filardi, V. Fogliano, M. D’Archivio, C. Giovannini, A. Lenzi, S. Morano and R. Masella. 2016. Consumption of extra-virgin olive oil rich in phenolic compounds improves metabolic control in patients with Type 2 diabetes mellitus: A possible involvement of reduced levels of circulating visfatin. J. Endocrinol. Invest. 39: 1295-1301.

Servili, M., A. Taticchi, S. Esposto, S. Urbani, R. Selvaggini and G. Montedoro. 2007. Effect of olive stoning on the volatile and phenolic composition of virgin olive oil. J. Agric. Food Chem. 55: 7028-7035.

Servili, M., S. Esposito, E. Lodolini, R. Selvaggini, A. Taticchi and S. Urbani. 2007. Irrigation effects on quality, phenolic composition, and selected volatiles of virgin olive oils cv. Leccino. J. Agric. Food Chem. 55: 6609-6618.

Servili, M., B. Sordini, S. Esposto, S. Urbani, G. Veneziani, I. Di Maio, R. Selvaggini and A. Taticchi. 2013. Biological activities of phenolic compounds of extra virgin olive oil. Antioxidants. 3: 1-23.
Sicari, V., A. M. Giuffrè, A. Piscopo and M. Poiana. 2009. Effect of the "Ottobratica" variety ripening stage on the phenolic profile of the obtained olive oil. Riv. Ital. Sostanze Gr. 86: 215-219.

Sicari, V., A. M. Giuffrè, L. Louadj and M. Poiana. 2010. Evolution of phenolic compounds of virgin olive oil during 12 months storage. Riv. Ital. Sostanze Gr. 87: 109-115.

Sicari V., M. R. Loizzo, V. Branca and T. M. Pellicanò. 2016. Evaluation of component bioactive and antioxidant activity from Citrus bergamia Risso (Bergamot) juice collected in different areas of Reggio Calabria province, Italy. Int. J. Food Prop. 19: 1962-1971.

Sicari, V. 2017. Antioxidant potential of extra virgin olive oils extracted from three different varieties cultivated in the Italian province of Reggio Calabria. J. Appl. Bot. Food Qual. 90: 76-82.

Sivitz, W. I., S. L. Desautel, T. Kayano, G. I. Bell and J. E. Pessin. 1989. Regulation of glucose transporter messenger RNA in insulin deficient states. Nature. 340: 72-74.

Sun, T. and S. A. Tanumihardjo. 2007. An integrated approach to evaluate food antioxidant capacity. J. Food Sci. 72: 159-165.

Tangvarasittichai, S. 2015. Oxidative stress, insulin resistance, dyslipidemia and Type 2 diabetes mellitus. World J. Diabetes. 6: 456-480.

Veneziani, G., S. Esposto, A. Taticchi, S. Urbani, R. Selvaggini, B. Sordini and M. Servili. 2018. Characterization of phenolic and volatile composition of extra virgin olive oil extracted from six Italian cultivars using a cooling treatment of olive paste. LWT. 87: 523-528.

Zeng, L., G. Zhang, S. Lin and D. Gong. 2016. Inhibitory mechanism of apigenin on a-glucosidase and synergy analysis of flavonoids. J. Agric. Food Chem. 64: 6939-6949. 